\title{
ASSESSING CHEATGRASS (BROMUS TECTORUM) GENETIC DIVERSITY AND POPULATION STRUCTURE USING RAPD AND MICROSATELLITE MOLECULAR MARKERS
}

\author{
Michael C. Ashley1,3 and William S. Longland ${ }^{1,2}$
}

\begin{abstract}
Two molecular marker systems, random amplified polymorphic DNA (RAPD) and microsatellites, were used to evaluate population diversity and differentiation in 4 northern Nevada Bromus tectorum populations. From 80 RAPD primers, we found $16(20 \%)$ that yielded 165 strong repeatable bands. Of those bands, $60(35.8 \%)$ were polymorphic. Of those, 21 met data-pruning guidelines for final analysis. RAPD variation was moderate $\left(\bar{x}=0.363, s_{\bar{x}}=0.022\right)$, ranging from 0.312 to 0.404 . Microsatellite variation was $\operatorname{similar}\left(\bar{x}=0.234, s_{\bar{x}}=0.051\right)$ but varied more widely, ranging from 0.009 to 0.551 . All populations were out of Hardy-Weinberg equilibrium, as expected in a predominantly selfing species. RAPDs revealed significant differentiation $(P<0.0001)$ across populations, whereas microsatellites only resolved 2 of the 4 populations. RAPDs revealed a considerable amount of variation in the 2 populations, Hot Springs and Truckee, which had nearly identical microsatellite profiles. Of 184 individuals, we found 182 unique RAPD phenotypes. We found 51 microsatellite genotypes across individuals, one of which was present in $95.3 \%$ of the individuals in the Hot Springs-Truckee group and $29 \%$ of the Stillwater individuals. The UPGMA phenograms were similar in grouping Hot Springs with Truckee, and Stillwater with Peavine, and were highly correlated but not significantly. Both marker systems proved useful in assessing population genetic variation. One population-specific RAPD marker and 6 new microsatellite-length polymorphisms were identified. Both marker systems may also prove useful in studying other closely related species such as red brome (Bromus rubens).
\end{abstract}

Key words: cheatgrass, diversity, evolution, population genetics, microsatellites, RAPD.

Molecular markers are powerful tools for studying population genetics (Haig 1998, Parker et al. 1998, Sunnucks 2000). Four frequently used marker systems are isozymes, random amplified polymorphic DNA (RAPD), amplified fragment length polymorphisms (AFLP), and microsatellites (Sunnucks 2000). The use of molecular markers to study population genetics of plants is widespread. For example, such markers have been applied to crop improvement (Virk et al. 2000, Ferdinandez et al. 2001), conservation (Cole and Kuchenreuther 2001, Mattner et al. 2002), and resistance to pesticides (Rutledge et al. 2000) and pathogens (Araújo et al. 2001, Levi et al. 2001, Ramakrishnan et al. 2004), the latter being important in crop and weed management. Molecular genetic studies employ from one (Rutledge et al. 2000, Ferdinandez et al. 2001, Novak 2004) to several (Russell et al. 1997, Sun et al. 1999, Virk et al. 2000) marker systems. Questions can be addressed at many levels of resolution, for example among accessions within a varietal group (Russell et al.
1997, Araújo et al. 2001), among populations (Green et al. 2001, Bartlett et al. 2002, Mattner et al. 2002, Ramakrishnan et al. 2004), and among species (Ferdinandez and Coulman 2002, Fu et al. 2002).

Microsatellites and RAPDs differ in the way they reveal genetic diversity. RAPDs amplify fragments that are dominant, meaning that both homozygous and heterozygous individuals produce a band, while homozygous nulls produce no band. This results in binary phenotypic (1/0) data (Williams et al. 1990, Sunnucks 2000). Direct detection of heterozygotes with these data is not possible (Williams et al. 1990, Sunnucks 2000), and estimation of heterozygosity is limited to non-inbreeding species in Hardy-Weinberg equilibrium (Lynch and Milligan 1994). RAPDs do allow for surveying many bands per decamer primer; they are relatively inexpensive and eliminate the time and expense of microsatellite primer development (Williams et al. 1990). Most microsatellite alleles, on the other hand, are codominant markers, meaning that every individual

\footnotetext{
${ }^{1}$ USDA / Agriculture Research Service / Exotic and Invasive Weeds Unit, 920 Valley Road, Reno, NV 89512

${ }^{2}$ Ecology, Evolution, and Conservation Biology Program, University of Nevada, Reno, 1664 North Virginia Street, Reno, NV 89557.

${ }^{3}$ E-mail: dr_mc_ashley@hotmail.com
} 
carries 2 alleles of the marker, allowing for identification of heterozygous individuals (Haig 1998, Parker et al. 1998, Sunnucks 2000).

Cheatgrass (Bromus tectorum) is a highly invasive exotic annual grass that has spread throughout North America, most heavily in the Intermountain West (Mack 1981, Novak et al. 1991), and has had enormous ecological impacts since its introduction to North America in the late 19th century (Young and Evans 1978, Knapp 1996, DiTomaso 2000). Differentiation of cheatgrass populations has been demonstrated with allozymes (Novak et al. 1991, Novak and Mack 2001, Bartlett et al. 2002, Novak 2004) and microsatellite markers (Ramakrishnan et al. 2002, Ramakrishnan et al. 2004, Ramakrishnan et al. 2006). Localized adaptation has been demonstrated with reciprocal planting (Rice and Mack 1991) and common garden studies (Meyer and Allen 1999). These studies all point to the tendency for cheatgrass populations to differentiate and sometimes develop adaptive allelic complexes.

Surveying the genetic variation of any species with a single molecular marker system may lead to erroneous conclusions, as one or more populations may be genetically different yet exhibit little or no variation relative to the marker employed (Ayers and Strong 2001). In a recent microsatellite study of heterozygosity in 4 cheatgrass populations from northern Nevada (Ashley and Longland 2007), we found 2 populations that, despite being assayed with 7 loci, exhibited both low genetic variation and lack of differentiation. Our goals for this paper are to use microsatellite and RAPD markers to evaluate genetic variation within and among 4 cheatgrass populations residing in different habitats and having different histories and to address the relative advantages and disadvantages of the 2 marker systems. This paper marks the first use of both microsatellites and RAPDs to evaluate population variation and differentiation in cheatgrass populations.

\section{Methods}

\section{Study Area}

We sampled individual plants in 2003 from 4 locations in northern Nevada: Hot Springs Mountains $\left(39^{\circ} 40^{\prime} \mathrm{N}, 119^{\circ} 05^{\prime} \mathrm{W}\right.$; Churchill County), Truckee Range $\left(39^{\circ} 40^{\prime} \mathrm{N}, 119^{\circ} 10^{\prime} \mathrm{W}\right.$; Churchill County), Peavine Mountain (39 $35^{\prime} \mathrm{N}$, $119^{\circ} 05^{\prime} \mathrm{W}$; Washoe County), and Stillwater Wildlife Refuge $\left(39^{\circ} 40^{\prime} \mathrm{N}, 118^{\circ} 35^{\prime} \mathrm{W}\right.$; Churchill County). The Hot Springs Mountains population (Hot Springs) is a semistable dune habitat supporting a salt desert shrub community typified by the genera Sarcobatus, Atriplex, and Tetrademia. The Hot Springs Mountains population is relatively new. Ecological studies of rodent-plant interactions had been ongoing since 1992, when cheatgrass was not present. Following 3 relatively wet years, cheatgrass invaded and became widespread by 1995 . The Truckee Range (Truckee) population is in an alluvial salt desert community and has been present for at least 20 years. Peavine Mountain (Peavine) supports both a long-standing cheatgrass population as well as a shrubsteppe community on alluvial soils, with sagebrush (Artemisia tridentata) as the dominant shrub. The Stillwater Wildlife Refuge (Stillwater) had been burned recently; the result was a virtual cheatgrass monoculture surrounded by a salt desert community with a clay-loam substrate. These 4 population collection sites also represent moderate elevation differences, with Stillwater at $\sim 1200 \mathrm{~m}$, Hot Springs at $\sim 1250 \mathrm{~m}$, Truckee Range at $\sim 1300 \mathrm{~m}$, and Peavine Mountain at $\sim 1650 \mathrm{~m}$.

\section{Sample Preparation}

We collected single plants $\geq 5 \mathrm{~m}$ apart, placed them individually in marked plastic bags, and stored them at $-80{ }^{\circ} \mathrm{C}$ until DNA extraction. We extracted DNA from green tissue (excluding seed heads and roots) ground under liquid nitrogen using a Qiagen DNEasy ${ }^{\circledR}$ Plant Mini Kit. DNA sample concentration was measured using an Eppendorf BioPhotometer. The bulk DNA samples were stored at $-80{ }^{\circ} \mathrm{C}$ while $10 \mu \mathrm{g} \cdot \mu \mathrm{L}^{-1}$ template aliquots were stored at $-10{ }^{\circ} \mathrm{C}$ until use.

\section{Microsatellite Techniques}

Eighteen species-specific microsatellite primer pairs were developed for Bromus tectorum by Ramakrishnan et al. (2002). Of those primer pairs 6 amplified poorly, 3 exhibited serious subbanding, 2 were monomorphic, and the remaining 7 amplified from 2 to 7 alleles across 4 populations screened for polymorphism (Ramakrishnan et al. 2002). We chose to use all 7 of those polymorphic microsatellite primers (Ramakrishnan et al. 2002) for our analyses. We amplified DNA products with a 
TABLE 1. Operon Technologies RAPD primers and band polymorphism profiles. In brackets are the values for polymorphic loci per primer that remained for use in the analysis after data pruning.

\begin{tabular}{llccc}
\hline Primer & Sequence $\left(5^{\prime}-3^{\prime}\right)$ & Bands $(n)$ & Polymorphic $(n)$ & \% Polymorphic \\
\hline A2 & TGCCGAGCTG & 6 & 3 & 50.00 \\
A4 & AATCGGGCTG & 9 & 3 & 33.33 \\
F3 & 7 & $4[3]$ & $57.14[42.85]$ \\
F4 & CCTGATCACC & 12 & $5[1]$ & $41.67[8.33]$ \\
F12 & GGTGATCAGG & 13 & 2 & $69.23[23.08]$ \\
F13 & ACGGTACCAG & 14 & $4[1]$ & 14.29 \\
F16 & GGCTGCAGAA & 8 & $6[2]$ & $50.00[12.50]$ \\
K4 & GGAGTACTGG & 7 & $1[1]$ & $85.71[28.57]$ \\
K7 & CCGCCCAAAC & 10 & 1 & $10.00[10.00]$ \\
K8 & AGCGAGCAAG & 7 & $5[4]$ & 14.29 \\
P3 & GAACACTGGG & 13 & $6[3]$ & $38.46[30.77]$ \\
P5 & CTGATACGCC & 12 & $3[2]$ & $50.00[25.00]$ \\
P9 & CCCCGGTAAC & 11 & 1 & $54.55[18.18]$ \\
P10 & GTGGTCCGCA & 8 & $1[1]$ & 37.50 \\
P12 & TCCCGCCTAC & 13 & $3.75[2.1]$ & 7.69 \\
P17 & ACGGTACCAG & 15 & $(0.58)[0.34]$ & $6.67[6.67]$ \\
Mean & TGACCCGCCT & 10.31 & $38.78[12.87]$ \\
$s_{\bar{x}}$ & & $(0.73)$ & $(5.83)[3.41]$ \\
\hline
\end{tabular}

Perkin Elmer GeneAmp 9600 PCR thermocycler, using Applied Biosystems Amplitaq Gold DNA polymerase and reagents. Following Ramakrishnan et al. (2002), we optimized the reactions by primer to attain strong band production in single primer reactions. Reaction volume was $25 \mu \mathrm{L}$ consisting of $2.5 \mu \mathrm{L} 10 \mathrm{X}$ reaction buffer, $2-3 \mu \mathrm{L}$ of $25 \mathrm{mM}$ magnesium chloride, $2 \mu \mathrm{L}$ dNTP mix $(2.5 \mathrm{mM}$ each dATP, dCTP, dGTP, and dTTp), 1-2 $\mu \mathrm{M}$ primer, 0.5 U DNA polymerase, $50 \mathrm{ng}$ DNA template, and deionized water to volume in a $0.2-\mathrm{mL}$ reaction tube. The PCR profile was 45 cycles of $95^{\circ} \mathrm{C}$ (1 minute), $60{ }^{\circ} \mathrm{C}$ (30 seconds), $72{ }^{\circ} \mathrm{C}(30$ seconds). Amplification was preceded by a polymerase activation cycle of $95{ }^{\circ} \mathrm{C}(10 \mathrm{~min}$ utes) and followed by a final extension cycle at $72{ }^{\circ} \mathrm{C}$ for 30 minutes. All primers had fluorescent labels ligated to either the forward or reverse primer for visualization and fragment size estimation by capillary electrophoresis on an ABI3730 automated sequencing machine along with $\mathrm{ABI} \mathrm{LIZ}^{\circledR}$ molecular size standard. We combined products from the singlet reactions into 2 multiplex plates for fragment analysis, the expected fragment lengths and dyes allowing for reliable fragment discrimination in the same run. The first multiplex combined NED-labeled Bt05, PET-labeled Bt 26, VIClabeled Bt30, and PET-labeled Bt33. The second multiplex combined PET-labeled Bt03, 6-FAM-labeled Bt04, and NED-labeled Bt12. The raw size data were analyzed using GeneScan ${ }^{\circledR}$ v.3.1 software. All putative hetero- zygotes were amplified and analyzed a second time.

\section{RAPD Techniques}

In a preliminary single population study of this species, we screened Operon Technology decamer primer sets $\mathrm{A}, \mathrm{F}, \mathrm{K}$, and $\mathrm{P}(n=80)$ for polymorphisms and found 16 primers that produced at least 1 strong repeatable variable band. That set of primers was employed in this study (Table 1). The amplification reactions were done with a Perkin-Elmer GeneAmp 9600 PCR thermocycler, using Applied Biosystems Amplitaq Gold ${ }^{\circledR}$ DNA polymerase and reagents. We optimized the reaction protocol for each of the primers, resulting in a general reaction cocktail consisting of $2.5 \mu \mathrm{L} \mathrm{10X} \mathrm{reac-}$ tion buffer, $2-3 \mu \mathrm{L}$ magnesium chloride, $2 \mu \mathrm{L}$ dNTP mix $(2.5 \mathrm{mM}$ each dATP, dCTP, dGTP, and dTTP), $1-2 \mu \mathrm{M}$ primer, $0.5 \mathrm{U}$ DNA polymerase, 50 ng DNA template, and deionized water to a final reaction volume of $25 \mu \mathrm{L}$ in a $0.2-\mathrm{mL}$ reaction tube. The PCR profile was 45 cycles of $95{ }^{\circ} \mathrm{C}$ ( 1 minute), 34 or $36^{\circ} \mathrm{C}(30 \mathrm{sec}-$ onds), a 7 -minute ramp to $72{ }^{\circ} \mathrm{C}$ (2 minutes) preceded by a polymerase activation cycle of $95{ }^{\circ} \mathrm{C}$ (10 minutes) and followed by a final extension cycle of $72{ }^{\circ} \mathrm{C}$ for 30 minutes.

All RAPD reactions were run and screened twice to ensure repeatability of bands, which were then evaluated for polymorphism. We separated the amplification products on $1.4 \%$ ethidium bromide-stained agarose minigels at $75 \mathrm{~V}$ for $20-30$ minutes and at $100 \mathrm{~V}$ for $1-1.5$ 


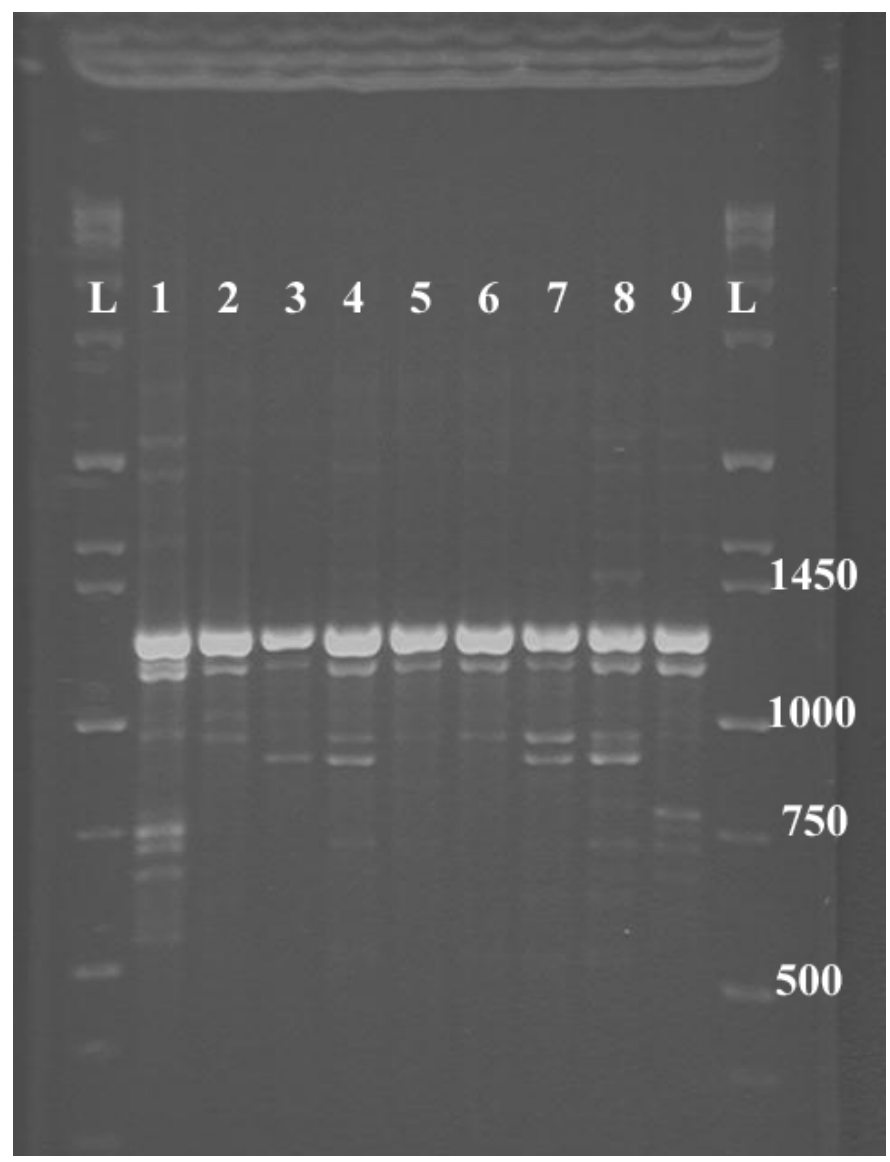

Fig. 1. Image of RAPD PCR products from 9 Peavine Mountain individuals for primer K4 visualized under ultraviolet light and ethidium bromide staining. "L" indicates lanes loaded with Hi-Lo ${ }^{\mathrm{TM}}$ molecular weight marker with 3 labeled bands.

hours, with run times adjusted for band lengths by primer. Each gel also contained 2 lanes loaded with $5 \mu \mathrm{L}$ of Minnesota Molecular Hi$\mathrm{Lo}^{\mathrm{TM}}$ DNA marker for fragment size estimation. We visualized the separated products with a GDS-8000 ChemiSystem ${ }^{\circledR}$ UV imaging system, and we estimated band sizes using UVP LabWorks 3.0 software (Fig. 1). All strong repeatable bands were counted for each primer, and polymorphic bands were scored for presence $(1)$ or absence $(0)$. Data pruning was applied to the polymorphic loci for all populations following Lynch and Milligan (1994): band frequency $<1-(3 / N)$.

\section{Data Analysis}

Microsatellite data were analyzed with TFPGA (Miller 1997), FSTAT (Goudet 1995), and Arlequin ${ }^{\circledR}$ (Excoffier et al. 2005) software packages. In TFPGA, Hardy-Weinberg equilibrium was estimated, following Guo and Thompson (1992), using an exact test employing a Monte Carlo random generation of alternate data distributions containing the same allele frequencies. Significance was determined by calculating the proportion of the random distributions that had conditional probabilities less than or equal to the conditional probability of the observed data. The Monte Carlo routine was run with 10 batches of 1000 permutations and 2000 dememorization steps. Population differentiation was evaluated in TFPGA as 2 $\times 2$ comparisons of genotype frequencies with a similarly parameterized Monte Carlo simulation. Genetic distance values and a phenogram for microsatellite data were produced in TFPGA following Nei’s (1978) unbiased minimum distance method. In FSTAT, population 
TABLE 2. Allelic lengths in base pairs and frequencies per locus of the 7 species-specific microsatellite markers used for the 4 study populations: Hot Springs, Truckee, Peavine, and Stillwater (from Ashley and Longland 2007).

\begin{tabular}{|c|c|c|c|c|c|}
\hline \multirow[b]{2}{*}{ Locus } & \multirow[b]{2}{*}{ Allele } & \multicolumn{4}{|c|}{ Population } \\
\hline & & Hot Springs & Truckee & Peavine & Stillwater \\
\hline \multirow[t]{5}{*}{$\overline{\mathrm{Bt} 03}$} & 108 & 0.000 & 0.000 & 0.000 & $0.097^{\dagger}$ \\
\hline & 110 & 1.000 & 0.960 & 0.742 & 0.419 \\
\hline & 112 & 0.000 & 0.040 & 0.258 & 0.387 \\
\hline & 114 & 0.000 & 0.000 & 0.000 & $0.065^{\dagger}$ \\
\hline & 126 & 0.000 & 0.000 & 0.000 & $0.032^{\dagger}$ \\
\hline Allele count & 5 & 1 & 2 & 2 & 5 \\
\hline \multirow[t]{4}{*}{ Bt04 } & 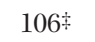 & 0.000 & 0.000 & 0.008 & 0.387 \\
\hline & 108 & 0.017 & 0.000 & 0.023 & 0.000 \\
\hline & 110 & 0.983 & 1.000 & 0.969 & 0.597 \\
\hline & 114 & 0.000 & 0.000 & 0.000 & $0.016^{\dagger}$ \\
\hline Allele count & 4 & 2 & 1 & 3 & 3 \\
\hline \multirow[t]{7}{*}{ Bt05 } & $161^{\ddagger}$ & 0.000 & $0.040^{\dagger}$ & 0.000 & 0.000 \\
\hline & 165 & 0.000 & 0.000 & $0.182^{\dagger}$ & 0.000 \\
\hline & 167 & 1.000 & 0.960 & 0.432 & 0.581 \\
\hline & 171 & 0.000 & 0.000 & $0.167^{\dagger}$ & 0.000 \\
\hline & 173 & 0.000 & 0.000 & 0.023 & 0.387 \\
\hline & 175 & 0.000 & 0.000 & 0.197 & 0.016 \\
\hline & 179 & 0.000 & 0.000 & 0.000 & $0.016^{\dagger}$ \\
\hline Allele count & 7 & 1 & 2 & 4 & 5 \\
\hline \multirow[t]{3}{*}{ Bt12 } & 248 & 1.000 & 1.000 & 0.924 & 0.516 \\
\hline & 258 & 0.000 & 0.000 & 0.000 & $0.064^{\dagger}$ \\
\hline & 260 & 0.000 & 0.000 & 0.076 & 0.420 \\
\hline Allele count & 3 & 1 & 1 & 2 & 3 \\
\hline \multirow[t]{9}{*}{ Bt26 } & $134^{\ddagger}$ & 0.000 & 0.000 & $0.038^{\dagger}$ & 0.000 \\
\hline & 146 & 0.000 & 0.040 & 0.417 & 0.129 \\
\hline & 150 & 0.000 & 0.000 & $0.538^{\dagger}$ & 0.000 \\
\hline & 152 & 0.000 & 0.000 & 0.000 & $0.081^{\dagger}$ \\
\hline & 154 & 0.000 & 0.000 & 0.000 & $0.371^{\dagger}$ \\
\hline & 156 & 0.000 & 0.000 & 0.000 & $0.016^{\dagger}$ \\
\hline & 158 & 0.000 & 0.000 & 0.000 & $0.016^{\dagger}$ \\
\hline & $160 \div$ & 0.017 & 0.000 & 0.008 & 0.032 \\
\hline & $162 \ddagger$ & 0.983 & 0.960 & 0.000 & 0.355 \\
\hline Allele count & 9 & 2 & 1 & 4 & 7 \\
\hline \multirow[t]{4}{*}{$\mathrm{Bt} 30$} & $106^{\ddagger}$ & 0.000 & 0.000 & 0.000 & $0.016^{\dagger}$ \\
\hline & 110 & 0.000 & 0.000 & 0.000 & $0.065^{\dagger}$ \\
\hline & 112 & 1.000 & 1.000 & 0.940 & 0.919 \\
\hline & 114 & 0.000 & 0.000 & $0.060^{\dagger}$ & 0.000 \\
\hline Allele count & 4 & 1 & 1 & 2 & 3 \\
\hline \multirow[t]{4}{*}{ Bt33 } & 219 & 0.000 & 0.040 & 0.788 & 0.452 \\
\hline & 221 & 0.000 & 0.000 & 0.000 & $0.065^{\dagger}$ \\
\hline & 223 & 0.000 & 0.000 & 0.212 & 0.129 \\
\hline & 225 & 1.000 & 0.960 & 0.000 & 0.355 \\
\hline Allele count & 4 & 2 & 2 & 2 & 4 \\
\hline
\end{tabular}

$\dagger$ Private alleles within the scope of the populations studied.

末Allele lengths beyond the ranges reported by Ramakrishnan et al. (2006).

specific $\mathrm{F}_{\text {IS }}$ was calculated using Weir and Cockerham's (1984) estimators of F-statistics. Gene diversity in FSTAT was summarized as the population mean of estimated heterozygosity at individual loci following Nei (1973) and adjusted for deviation from Hardy-Weinberg equilibrium by substituting $n$ for $2 n$ in the basic calculation following Nei (1978). Population-specific descriptive statistics produced with FSTAT were used to summarize the parameters A (average number of alleles per locus) and $\mathrm{P}$ (proportion of polymorphic loci). Pairwise $\mathrm{F}_{\mathrm{ST}}$ estimates and population-level genetic evaluations were produced in Arlequin ${ }^{(0}$ 
TABLE 3. Estimated mean $\left(s_{\bar{x}}\right)$ microsatellite diversity (Nei 1973, 1978) and relative rank for both markers for 4 northern Nevada cheatgrass populations.

\begin{tabular}{lccc}
\hline Population & Microsatellite & RAPD & Rank \\
\hline Hot Springs & $0.009(0.006)$ & $0.312(0.158)$ & 4,4 \\
Truckee & $0.046(0.016)$ & $0.353(0.140)$ & 3,2 \\
Stillwater & $0.551(0.073)$ & $0.331(0.174)$ & 1,3 \\
Peavine & $0.330(0.092)$ & $0.404(0.108)$ & 2,1 \\
Across populations & $0.234(0.051)$ & $0.363(0.022)$ & \\
\hline
\end{tabular}

(Excoffier et al. 2005) from which the parameters $\mathrm{H}_{\mathrm{e}}$ (expected heterozygosity) and $\mathrm{H}_{\mathrm{o}}$ (observed heterozygosity) were summarized.

RAPD data were analyzed with TFPGA (Miller 1997), Arlequin ${ }^{\circledR}$ (Excoffier et al. 2005), and PopGene v1.31 (Yeh and Boyle 1997). Population differentiation was evaluated in TFPGA as described above with RAPD phenotypes rather than microsatellite genotypes. Genetic distance values and a phenogram for RAPD data were constructed in the same manner as for microsatellites. As with the microsatellite data, pairwise $\mathrm{F}_{\mathrm{ST}}$ estimates were generated using Arlequin ${ }^{\circledR}$ (Excoffier et al. 2005) software.

Although TFPGA utilizes dominant marker analyses following Lynch and Milligan (1994), this software assumes Hardy-Weinberg equilibrium by default, thereby overreporting expected heterozygosity. We estimated $q$ (estimated frequency of the null allele) from RAPD data following Lynch and Milligan (1994) and employed their equation for estimating expected heterozygosity:

$$
P_{\mathrm{Mm}}=2 p q\left(1-\mathrm{F}_{\mathrm{IS}}\right) \text {, }
$$

with the population level $\mathrm{F}_{\text {IS }}$ values derived from the analysis of microsatellite data with FSTAT and $p=1-q$. Doing so allowed us to estimate mean heterozygosity while making an allowance for departure from Hardy-Weinberg equilibrium. Population-level gene diversity values were generated from the RAPD data with Popgene v1.31 (Yeh and Boyle 1997), which can calculate the estimates without the assumption of Hardy-Weinberg equilibrium.

Partitioning of variation by analysis of molecular variance (AMOVA) was conducted for both marker types in Arlequin ${ }^{\circledR}$ (Excoffier et al. 2005) with the RAPD phenotypes analyzed as binary haplotypes, equivalent to RFLP data. As heterozygosity cannot be determined with RAPDs, variance partitioning was restricted to among individuals within populations, and among populations. Microsatellites, however, can detect heterozygosity, allowing for partitioning of variance among populations, within populations, and within individuals. The microsatellite and RAPD distance matrices were tested for significant correlation with a Mantel test in TFPGA.

\section{RESUlTS}

\section{Molecular Polymorphisms}

Microsatellite amplifications produced from 3 to 9 alleles per locus and from 1 to 5 alleles per locus per population (Table 2; Ashley and Longland 2007). All of the microsatellite loci revealed polymorphisms in at least one of the populations (Table 2). The RAPD primer set yielded 165 strong repeatable bands (loci) of which $60(35.8 \%)$ were variable. Percent of polymorphic bands per RAPD primer ranged from 6.67 to $85.71\left(\bar{x}=38.8, s_{\bar{x}}=5.83\right.$; Table 1$)$. The frequency of homozygous null individuals ranged from 0.033 to 0.870 across loci $(\bar{x}=$ $\left.0.414, s_{\bar{x}}=0.028\right)$. Not all of the markers were polymorphic across populations. Hot Springs had 16 fixed loci (26.6\%), Truckee had 12 (20\%), Stillwater had $8(13.33 \%)$, and Peavine had only $4(6 \%)$. Twenty-four $(40.0 \%)$ of the 60 loci were fixed in one or more populations, with an average number of fixed populations per locus of $1.333\left(s_{\bar{x}}=0.105\right)$. There were, as well, nearly twice as many null (26) as dominant (14) allele fixations. Where loci were fixed for one or more populations, the average proportion of null alleles for the variable population(s) fell between 0.05 and 0.95 , with an average across loci of $0.401\left(s_{\bar{x}}=0.027\right)$. All of the loci were polymorphic for at least one population, with a dominant marker or null homozygote at a frequency within the data-pruning parameter, band frequency $<1-(3 / N)$, set forth by Lynch and Milligan (1994). However, when that criterion was extended to all loci for all populations, data pruning reduced the number of loci suitable for analysis to 21 . For the remaining set of polymorphic loci, the percentage of polymorphic bands per RAPD primer ranged from 6.67 to $42.85\left(\bar{x}=12.9, s_{\bar{x}}=3.41\right.$; Table 1$)$

\section{Molecular Diversity}

Microsatellite diversity, a measure of heterozygosity, was more unevenly distributed than diversity of RAPDs in these populations. Mean 
TABLE 4. Estimated means $\left(s_{\bar{x}}\right)$ of the microsatellite parameters A (average number of alleles per locus), $\mathrm{P}$ (proportion of polymorphic loci), $\mathrm{H}_{\mathrm{e}}$ (expected heterozygosity), and $\mathrm{H}_{\mathrm{o}}$ (observed heterozygosity).

\begin{tabular}{lcccc}
\hline & $\mathrm{A}$ & $\mathrm{P}$ & $\mathrm{H}_{\mathrm{e}}$ & $\mathrm{H}_{\mathrm{o}}$ \\
\hline Hot Springs & $1.286(0.184)$ & $0.286(0.184)$ & $0.018(0.014)$ & $0.000(0.000)$ \\
Truckee & $1.571(0.202)$ & $0.571(0.202)$ & $0.006(0.004)$ & $0.000(0.000)$ \\
Stillwater & $2.857(0.459)$ & $1.000(0.000)$ & $0.352(0.088)$ & $0.022(0.009)$ \\
Peavine & $4.143(0.553)$ & $1.000(0.000)$ & $0.547(0.073)$ & $0.060(0.026)$ \\
\hline
\end{tabular}

a. Genetic Distance
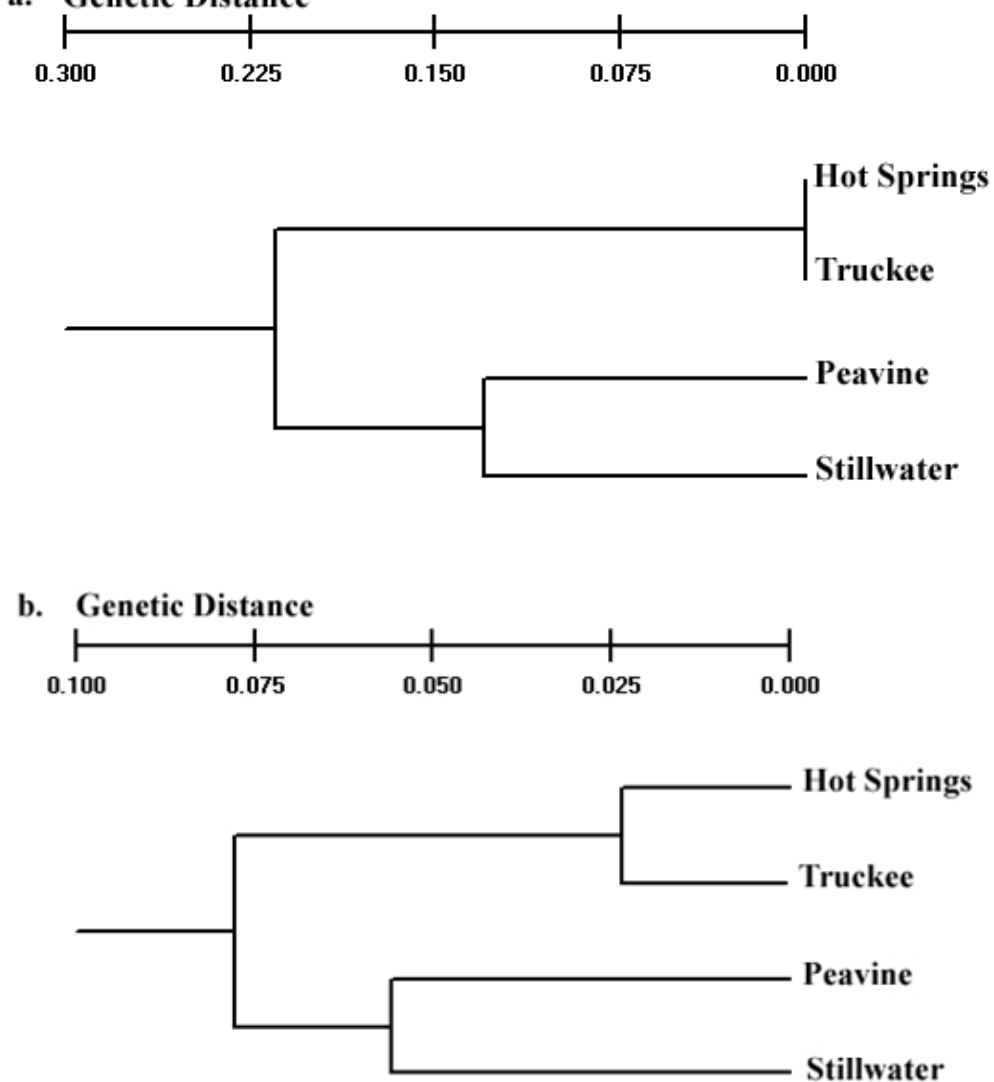

Fig. 2. UPGMA Nei (1978) minimum distance method phenograms created in TFPGA software (Miller 1997) from microsatellite data (a) and RAPD data (b) for 4 cheatgrass populations in northern Nevada.

microsatellite diversity across populations was $0.234\left(s_{\bar{x}}=0.051\right)$, ranging from 0.009 to 0.551 within populations (Table 3). Hot Springs and Truckee populations had very low diversity $\left(\bar{x}=0.028, s_{\bar{x}}=0.009\right)$, while Stillwater and Peavine were considerably more diverse $\left(\bar{x}=0.441, s_{\bar{x}}=0.064\right)$. RAPDs revealed relatively higher mean diversity $(\bar{x}=$ $0.363, s_{\bar{x}}=0.22$ ), with higher values for Hot Springs, Truckee, and Peavine and lower values for Stillwater (Table 3), compared to microsatellites. Hot Springs was the only pop- ulation that retained its diversity rank for both markers (Table 3). Microsatellite measures of the parameters $\mathrm{A}, \mathrm{P}, \mathrm{H}_{\mathrm{e}}$, and $\mathrm{H}_{\mathrm{o}}$ varied in a fashion similar to microsatellite diversity measures for the 4 populations (Table 4).

Phenotypic (RAPD) and genotypic (microsatellite) distributions were dissimilar as well. Virtually all the individuals (180 of 184, 97.8\%) had unique RAPD phenotypes, with 1 phenotype shared by 2 individuals from Hot Springs and 1 phenotype shared by 2 individuals from Peavine Mountain. We found 49 separate 
TABLE 5. Matrix of pairwise $\mathrm{F}_{\mathrm{ST}}$ values obtained from microsatellite and RAPD data for 4 northern Nevada cheatgrass populations. Microsatellite values are above the diagonal and RAPD values are below the diagonal.

\begin{tabular}{llllc}
\hline & Hot Springs & Truckee & Stillwater & Peavine \\
\hline Hot Springs & & 0.0236 & $0.5212^{* * * *}$ & $0.5679 * * *$ \\
Truckee & $0.1056^{* * *}$ & & $0.4152^{* * * *}$ & $0.5042^{* * *}$ \\
Stillwater & $0.2034^{* * *}$ & $0.2313^{* * *}$ & & $0.2514^{* * *}$ \\
Peavine & $0.2281^{* * *}$ & $0.1904 * * *$ & $0.1557 * * *$ & \\
\hline
\end{tabular}

*** $P(0.0001)$ based on 10,000 permutations

TABLE 6. Matrix of genetic Nei's (1978) unbiased minimum distance measures obtained from microsatellite and RAPD data for 4 northern Nevada cheatgrass populations. Microsatellite measures are above the diagonal and RAPD measures are below the diagonal.

\begin{tabular}{lcccc}
\hline & Hot Springs & Truckee & Stillwater & Peavine \\
\hline Hot Springs & & 0.0001 & 0.1815 & 0.2490 \\
Truckee & 0.0234 & 0.0735 & 0.1783 & 0.2479 \\
Stillwater & 0.0610 & 0.0873 & 0.0557 & 0.1304 \\
Peavine & 0.0895 & & \\
\hline
\end{tabular}

TABLE 7. Results of AMOVA analyses partitioning variance proportions in 4 northern Nevada cheatgrass populations as assessed with microsatellite (7 loci) and RAPD data (21 loci). All results were significant at $P<0.05$.

\begin{tabular}{lccc}
\hline Marker system & $\begin{array}{c}\text { Among } \\
\text { populations }\end{array}$ & $\begin{array}{c}\text { Within } \\
\text { populations }\end{array}$ & $\begin{array}{c}\text { Within } \\
\text { individuals }\end{array}$ \\
\hline RAPD & 0.194 & 0.806 & N/A \\
Microsatellite & 0.454 & 0.503 & 0.043 \\
\hline
\end{tabular}

microsatellite genotypes; however, Hot Springs and Truckee were almost uniform with only 5 genotypes between them, and 1 genotype was common to $94.1 \%$ of the 2 populations combined. Stillwater had 14 genotypes, with a range of 1-6 individuals per genotype; one of these genotypes was shared by 9 individuals and was identical to the dominant Hot Springs / Truckee genotype. Peavine had 31 genotypes, with a range of $1-10$ individuals per genotype. Estimated mean $\left(s_{\bar{x}}\right)$ heterozygosity for RAPD data following Lynch and Milligan (1994) was relatively low: Hot Springs, $\bar{x}=0.00(0.00)$, Truckee, $\bar{x}=0.00$ $(0.00)$, Stillwater, $\bar{x}=0.032(0.005)$, and Peavine, $\bar{x}=0.027(0.002)$. All populations were significantly out of Hardy-Weinberg equilibrium for both marker systems $(\mathrm{P}<0.0001)$, as can be expected in a predominantly selfing species.

\section{Population Differentiation}

All populations were significantly differentiated with RAPD markers $(P<0.0001)$. The analysis of microsatellite data grouped Hot Springs and Truckee tightly (i.e., nondifferen- tiation), with Peavine and Stillwater forming a group while still being significantly differentiated from each other and the Hot SpringsTruckee complex (Fig. 2), as is also evident from pairwise $\mathrm{F}_{\mathrm{ST}}$ (Table 5) and distance measures (Table 6). RAPDs and microsatellites both produced UPGMA phenograms in which Stillwater and Peavine were grouped and Hot Springs and Truckee were grouped (Fig. 2). We compared the 2 distance matrices with a Mantel test and found a positive correlation $(r=0.954)$ that was nearly significant $(Z=$ $0.1039,999$ permutations, $P=0.075)$. AMOVAs on microsatellites and RAPDs partitioned the majority of the variation within populations rather than among populations (Table 7). A small amount of microsatellite variance was partitioned within individuals, as we found heterozygotes at Stillwater and Peavine (Table 7).

In the full set of polymorphic RAPD loci, we found none that had bands that were uniformly expressed in one population while being totally absent in the others. Nor did we find a population that was fixed for the homozygous null for a locus that was fixed for the dominant band in the remaining populations. Had either of these 2 conditions been met, we would have found a diagnostic population-specific marker. However, we did find one locus, P3 allele $5(\sim 585 \mathrm{bp})$, with bands present only in the Peavine population but at an intermediate frequency $(0.64)$. With microsatellites, we found 3 rare (frequency < 0.05 ) private alleles, one each in the Truckee, Stillwater, and 
Peavine populations (Table 2; Ashley and Longland 2007).

\section{Discussion}

\section{Molecular Polymorphisms}

We found the combination of microsatellite and polymorphic RAPD loci to be effective for assessing both genetic diversity and population differentiation in cheatgrass. The number of RAPD fixations per population correlated inversely to genetic diversity ranking (i.e., more fixations with low molecular diversity and fewer with high diversity). The low number of populations per fixed locus $\left(1.333, s_{\bar{x}}=0.105\right)$ indicates a broad distribution of fixations among populations. Such fixed loci, especially nulls, provide a ready method of identifying immigration and, more rarely, mutation events at primer binding sites. Such events can be inferred when a band appears where none had been present before (fixed null locus) or a null appears when none had appeared before (fixed dominant locus). We feel that RAPD markers will be useful in assessing additional cheatgrass populations across the Great Basin and Intermountain West. From such assessments, we expect not only to develop a better understanding of the range of cheatgrass population diversity but also perhaps identify population-specific markers. Such markers may prove useful in future management efforts if populations bearing these markers possess traits such as pathogen or herbicide resistance and the trait and marker are linked-a direction for further research. Similar work has been done with microsatellites where resistance to the head smut pathogen Ustillago bullata in a population was closely linked to a particular microsatellite genotype (Ramakrishnan et al. 2004).

\section{Diversity and Differentiation}

All populations had some degree of genetic differentiation (Table 3), and as expected with predominantly self-pollinators, all populations were out of Hardy-Weinberg equilibrium ( $P$ $<0.0001)$. RAPDs revealed considerably more overall genetic variation in both the Hot Springs and Truckee populations than was estimated with microsatellites (Table 3). This is similar to the case of AFLPs revealing variation in cheatgrass populations with low microsatellite diversity (Ramakrishnan et al. 2004).
Conversely, in a multiple marker study of barley (Hordeum vulgaris) accessions, RAPDs produced lower diversity indices than microsatellites did, whereas AFLPs had higher diversity than both other markers (Russell et al. 1997). RAPD diversity indices for cheatgrass were within the range of those reported for isozymes (Novak et al. 1991) and AFLPs (Ramakrishnan et al. 2004). However, the ranges of microsatellite allele sizes we found exceeded those for 4 of the microsatellite loci reported in Ramakrishnan et al. (2006). For one locus, Bt26, we found both shorter and longer allele lengths than previously reported. For $\mathrm{Bt} 04, \mathrm{Bt} 05$, and $\mathrm{Bt} 30$ we found new shorter allele lengths. Not surprisingly, the relative ranking of RAPD diversity measures among the 4 populations varied from those derived from microsatellites with the exception of Hot Springs, as these are different marker systems and many more RAPD loci were analyzed than microsatellite loci (Table 3).

The partitioning of genetic variation within populations of cheatgrass varies from study to study. Pyke and Novak (1992), using protein electrophoresis, reported that for introduced cheatgrass populations in North America, 52.2\% of genetic variation was partitioned within populations, more than half of the total variation and twice as much as they found for native populations, $25.1 \%$. Ramakrishnan et al. (2004) found much more diversity partitioned within populations for AFLP markers (44.2\%) than for microsatellites (16.7\%). Similarly, our study found more within-population diversity for RAPDs than for microsatellites, but in both cases more than half of the total variation was partitioned within populations (Table 7). The presence of heterozygotes partitions a small amount of the total variation within individuals but does not make up the difference of within-population variability between microsatellites and RAPDs (Table 7). The very large proportion of within-population variability we found with RAPDs is likely due in part to the large number of loci (21) we examined. This is the first study using microsatellites together with RAPDs that corroborates the high withinpopulation variability found in naturalized populations examined with AFLPs and allozymes.

The near absence of intraspecific and interpopulation differentiation at Hot Springs and Truckee as evaluated with microsatellites may be tied to the genetic makeup of the founding 
population(s) or it could be an artifact of past bottleneck event(s), analogous to a founder event where initial variation is reduced by incomplete sampling followed by fixation at some loci caused by genetic drift and predominant selfing. The lower microsatellite variation at Hot Springs relative to Truckee may be the result of one or both scenarios. The Hot Springs population is relatively new (circa 1994), as it only became widespread in 1995 (founder event). Then the population crashed in 2000 only to rebound in 2002 (bottleneck). By virtue of proximity, the Truckee population was a likely source for some if not all of the microsatellite variation in the new Hot Springs population. A bottleneck event shortly after establishment would only serve to reduce overall variation at Hot Springs.

So, why is there so much RAPD variation at Hot Springs and Truckee? Even though cheatgrass is a predominant selfer, we have found direct evidence of outcrossing in 2 populations, Stillwater and Peavine (Ashley and Longland 2007). Assuming that Hot Springs and Truckee had the same source population and that microsatellite diversity was low and fixed for a majority of the loci, outcrossing in that population, however frequent, is masked by the initial conditions (i.e., lack of allelic diversity). Many individuals that were products of outcrossing may have been homozygous at a particular microsatellite locus, yet they may have had alleles that were not identical by descent (silent heterozygosity). Those same individuals, however, inherited the remaining genetic variation of their parents (beyond microsatellite loci) and likely reorganized that variation through occasional outcrossing, crossovers, consolidations, and subsequent self-pollinations. In a population where predominant selfing is punctuated by outcrossing and where new gene variants are contributed by mutation and dispersal, a significant degree of intraspecific variation could build up across generations to the point where 2 highly similar populations by one metric (microsatellites) are divergent by another metric (RAPDs). We suspect that the individuality of the RAPD phenotypes we found is evidence of such past outcrossing events. Because they observed rare microsatellite genotypes in their recent cheatgrass study, Ramakrishnan et al. (2006) acknowledged the possibility of past outcrossing events. Such genetic variation may or may not have direct ecologi- cal or managerial importance, as both marker systems are effectively neutral. However, it may be imprudent to assume that low variation for one marker system extends to the genome as a whole. By employing more than one marker system, investigators may be able to more accurately evaluate population variation.

Although we have compared the results obtained from these 2 data types, it is important to point out the differences that exist between these marker systems. RAPDs are CG rich $(\geq 50 \%)$ by design, and the primers we used averaged $63.8 \%\left(s_{\bar{x}}=1.3\right)$, while the microsatellite primers only averaged $51.2 \%\left(s_{\bar{x}}\right.$ $=2.9$ ). Additionally, the microsatellite stretches themselves are mostly CA and CT repeat units, with the rest being GT, AG, and AGG units, richer in C (4 of 7 at 50\% each) than in G (2 of 7 at $50 \%$ and $54 \%$ ). These differences likely lead to the sampling of different portions of the cheatgrass genome. These likely different areas of sampling may themselves be prone to different mutation rates, as some may contain genes under selection or highly conserved stretches of sequence subject to DNA repair mechanisms. Mutation mechanisms may also play a part in the differences between these 2 markers. Microsatellite alleles are determined by fragment length, which can mutate by slippage during replication, by addition or subtraction of a repeat unit, with rates as high as $5 \times 10^{-3}$ per allele per generation (Huang et al. 1992). RAPDs, on the other hand, are more susceptible to spontaneous mutations that can eliminate or create a priming site for amplification of an allele. However, spontaneous mutations typically occur at a much slower rate, from $1 \times 10^{-4}$ to $1 \times 10^{-6}$ allele per generation (Hartl and Clark 1989). Additionally, insertions and duplications may create or eliminate RAPD alleles.

The results of this study support the merits of using multiple markers for assessing genetic diversity, as it seems "no one size fits all." Each molecular marker brings to the table its own set of strengths and weaknesses. If one must rely on a single marker system, there are potential trade-offs relative to the study itself: data type, resolution, comparability, and cost (Haig 1998, Parker et al. 1998, Sunnucks 2000). Applying multiple markers when feasible eliminates some of those trade-offs and offers potentially better resolution of population genetic parameters, especially when one marker falls 
short (e.g., widespread fixation). The results of this study justify a broader survey of cheatgrass populations with these markers, both across and outside of the Great Basin and spanning multiple habitat types. Beyond cheatgrass, these markers may prove useful in surveying other closely related species such as red brome (Bromus rubens), another exotic and invasive annual grass that is rapidly expanding its range in the southwestern United States (Hunter 1991, Salo 2005).

\section{ACKNOWLEDGMENTS}

This study was supported in part by the USDA/ARS Exotic and Invasive Weed Unit and NIH Grant Number P20 RR-016464 from the INBRE Program of the National Center for Research. We thank Robin Tausch, Matt Forister, and 2 anonymous reviewers for manuscript comments and suggestions.

\section{Literature Cited}

Araújo, L.G., A.S. Prabhu, M.C. Filippi, and L.J. Chaves. 2001. RAPD analysis of blast resistant somaclones from upland rice cultivar IAC 47 for genetic divergence. Plant Cell, Tissue, and Organ Culture 67: $165-172$.

Ashley, M.C., AND W.S. Longland. 2007. Microsatellite evidence of facultative outcrossing in cheatgrass (Bromus tectorum): implications for the evolution of invasiveness. Plant Species Biology 22:197-204.

Ayers, D.R., AND D.R. Strong. 2001. Origin and genetic diversity of Spartina anglica (Poaceae) using nuclear DNA markers. American Journal of Botany 88:1863-1867.

Bartlett, E., S.J. Novak, AND R.N. Mack. 2002. Genetic variation in Bromus tectorum (Poaceae): differentiation in the eastern United States. American Journal of Botany 89:602-612.

Cole, C.T., And M.A. Kuchenreuther. 2001. Molecular markers reveal little genetic differentiation among A. conitum novemboracense and A. columbianum (Ranunculaceae) populations. American Journal of Botany 88:337-347.

DiTomaso, J.M. 2000. Invasive weeds in rangelands: species, impacts, and management. Weed Science 48:255-265.

Excoffier, L.G., G. Laval, and S. Schneider. 2005. Arlequin version 3.0: an integrated software package for population genetics data analysis. Evolutionary Bioinformatics Online 1:47-50.

FERdinandez, Y.S.N., AND B.E. Coulman. 2002. Evaluating genetic variation and relationships among two bromegrass species and their hybrid using RAPD and AFLP markers. Euphytica 125:281-291.

Ferdinandez, Y.S.N, D.J. Somers, and B.E. Coulman. 2001. Estimating the genetic relationship of hybrid bromegrass to smooth bromegrass and meadow bromegrass using RAPD markers. Plant Breeding 120:149-153.

Fu, Y.-B., G. Peterson, A. Diederichsen, and K.W. RICHARDS. 2002. RAPD analysis of genetic relationships of seven flax species in the genus Linum L. Genetic Resources and Crop Evolution 49:253-259.

GoudET, J. 1995. FSTAT (version 1.2): a computer program to calculate F-statistics. Heredity 86:485-486.

Guo, S.W., And E.A. Thompson. 1992. Performing exact tests of Hardy-Weinberg proportion for multiple alleles. Biometrics 48:361-372.

Green, J.M., J.H.A. Barker, E.J.P. Marshall, R.J. Froud-Williams, N.C.B. Peters, G.M. Arnold, K. DaWson, AND A. KARP. 2001. Microsatellite analysis of the inbreeding grass weed barren brome (Anisantha sterilis) reveals genetic diversity at the withinand between-farm scales. Molecular Ecology 10: 1035-1045.

HaIG, S.M. 1998. Molecular contributions to conservation. Ecology 79:413-425.

Hartl, D.L., and A.G. Clark. 1989. Principles of population genetics. 2nd edition. Sinauer Associates, Inc., Sunderland, MA. 682 pp.

Huang, T.H.-M., R.W. Cottingham, Jr., D.H. Ledbetter, AND H.Y. ZoGHBI. 1992. Genetic mapping of four sinucleotide repeat loci, DXS453, DSX458, DSX454, and DSX424, on the X chromosome using multiplex polymerase chain reaction. Genomics 13:375-380.

Hunter, R. 1991. Bromus invasions on the Nevada Test Site-present status of B. rubens and B. tectorum with notes on their relationship to disturbance and altitude. Great Basin Naturalist 51:176-182.

KNAPP, P.A. 1996. Cheatgrass (Bromus tectorum L) dominance in the Great Basin. Global Environmental Change 6:37-52.

Levi, A., C.E. Thomas, A.P. Keinath, and T.C. Wehner. 2001. Genetic diversity among watermelon (Citrullus lanatus and Citrullus colocynthis) accessions. Genetic Resources and Crop Evolution 48:559-566.

LynCH, M., AND B.G. Milligan. 1994. Analysis of population genetic structure with RAPD markers. Molecular Ecology 3:91-99.

MACK, R.N. 1981. Invasion of Bromus tectorum L. into western North America: an ecological chronicle. Agro-Ecosystems 7:145-165.

Mattner, J., G. Zawko, M. Rosetto, S.L. Krauss, K.W. DiXon, AND K. Sivasithamparam. 2002. Conservation genetics and implications for restoration of Hemigenia exelis (Lamiaceae), a serpentine endemic from Western Australia. Biological Conservation 107:37-45.

Meyer, S.E., AND P.S. AlLEN. 1999. Ecological genetics of seed germination regulation in Bromus tectorum L. I. Phenotypic variance among and within populations. Oecologia 120:27-34.

Miller, M.P. 1997. Tools for population genetic analysis (TFPGA) 1.3: a Windows program for the analysis of allozyme and molecular population genetic data. Software distributed by the author. Available from: http://www.marksgeneticsoftware.net/.

NEI, M. 1973. Analysis of gene diversity in subdivided populations. Proceedings of the National Academy of Sciences 70:3321-3323.

NEI, M. 1978. Estimation of average heterozygosity and genetic distance from a small number of individuals. Genetics 89:583-590. 
NOVAK, S.J. 2004. Genetic analysis of downy brome (Bromus tectorum) and medusahead (Taeniatherum caputmedusae): management implications. Weed Technology 18:1417-1421.

NovaK, S.J., AND R.N. Mack. 2001. Tracing plant introduction and spread: genetic evidence from Bromus tectorum (cheatgrass). BioScience 51:114-122

NovaK, S.J., R.N. Mack, AND D.E. Soltis. 1991. Genetic variation in Bromus tectorum (Poaceae): population differentiation in its North American range. American Journal of Botany 78:1150-1161.

Parker, P.G., A.A. Snow, M.D. Schug, G.C. Booton, AND P.A. Fuerst. 1998. What molecules can tell us about populations: choosing and using a molecular marker. Ecology 79:361-382.

Pyke, D.A., AND S.J. NovaK. 1992. Cheatgrass demography-establishment attributes, recruitment, ecotypes, and genetic variability. In S.B. Monsen and S.G. Kitchen, editors, Proceedings-Ecology and Management of Annual Rangelands. INT-GTR- 313, USDA Forest Service, Intermountain Research Station, Ogden, UT.

Ramakrishnan, A.P., C.E. Coleman, S.E. Meyer, and D.J. Fairbanks. 2002. Microsatellite markers for Bromus tectorum (cheatgrass). Molecular Ecology Notes 2:22-23.

Ramakrishnan, A.P., S.E. Meyer, D.J. Fairbanks, and C.E. Coleman. 2006. Ecological significance of microsatellite variation in western North American populations of Bromus tectorum. Plant Species Biology 21:61-73.

Ramakrishnan, A.P., S.E. Meyer, J.W. Waters, M.R. Stevens, C.E. Coleman, and D.J. Fairbanks. 2004. Correlation between molecular markers and adaptively significant genetic variation in Bromus tectorum (Poaceae), an inbreeding annual grass. American Journal of Botany 91:797-803.

Rice, J.R., AND R.N. MaCK. 1991. Ecological genetics of Bromus tectorum. III. The demography of reciprocally sown populations. Oecologia 88:91-101.

Russell, J.R., J.D. Fuller, M. Macaulay, B.G. Hatz, A. Jahoor, W. Powell, and R. Waugh. 1997. Direct comparisons of levels of genetic variation among barley accessions detected by RFLPs, AFLPs, SSRs, and RAPDs. Theoretical and Applied Genetics 95: 714-722.

Rutledge, J., R.E. Talbert, and C.H. Sneller. 2000. RAPD analysis of genetic variation among propanilresistant and -susceptible Echinochloa crus-galli populations in Arkansas. Weed Science 48:669-674.

SALO, L.F. 2005. Red brome (Bromus rubens subsp madritensis) in North America: possible modes for early introductions, subsequent spread. Biological Invasions 7:165-180.

Sun, G.-L., O. Diaz, B. Salomon, and R. von Bothmer. 1999. Genetic diversity in Elymus caninus as revealed by isozyme, RAPD, and microsatellite markers. Genome 42:420-431.

SunNuCKs, P. 2000. Efficient genetic markers for population biology. Trends in Ecology and Evolution 15: 199-203.

Virk, P.S., J. Zhu, H.J. Newbury, G.J. Bryan, M.T. JaCKSON, AND B.V. FORD-LLOYD. 2000. Effectiveness of different classes of molecular marker for classifying and revealing variation in rice (Oryza sativa) germplasm. Euphytica 112:275-284.

Weir, B.S., and C.C. Cockerham. 1984. Estimating Fstatistics for the analysis of population structure. Evolution 38:1358-1370.

Williams, J.G.K., A.R. Kubelik, K.J. Livak, and S.V. TINGEY. 1990. DNA polymorphisms amplified by arbitrary primers are useful genetic markers. Nucleic Acids Research 18:6531-6535.

YEH, F.C., AND T.J.B. BoYLE. 1997. Population genetic analysis of co-dominant and dominant markers and quantitative traits. Belgian Journal of Botany 129: 157.

Young, J.A., AND R.A. Evans. 1978. Population dynamics after wildfires in sagebrush grasslands. Journal of Range Management 31:283-289.

Received 8 August 2007 Accepted 12 September 2008 